\title{
Pneumococcal vaccine
}

Vaccination against pneumococcal pneumonia has a long history.' It began with a whole cell vaccine 70 years ago and developed through the discovery of pneumococcal typing and subdivision of the species by capsular antigens. This led to passive immunisation as a form of treatment and to the first type specific vaccines in the 1930s. After the introduction of - sulphonamides and antibiotics there was less interest in serum treatment and vaccination. The death rate in the first five days of an attack of bacteraemic pneumonia was not decreased, however, and the case fatality rate from pneumococcal bacteraemia remained a substantial $20 \%$. ${ }^{2}$ So research continued to make purified polysaccharide multiple type (polyvalent) vaccines and these proved to be successful in trials reported 10 years ago ${ }^{34}$ Further developments increased the range of pneumococcal types covered by the vaccines-from six to $12,14,17$, and now 23 types. These modern vaccines deserve more attention than they have received outside the United States.

\section{Risks of pneumococcal infection}

The incidence of pneumococcal pneumonia in Britain is about $1 / 1000$ a year, to judge by the 1984-5 Nottingham study. ${ }^{5}$ In another study in the same city ${ }^{6}$ the mortality from community acquired pneumococcal pneumonia treated in hospital was $18 \%$, a figure that echoes case fatality rates in New York 20 years earlier. ${ }^{2}$ The incidence is more than 10 times higher in the elderly and in patients with asplenism, Hodgkin's disease, myeloma, heart disease, chronic obstructive pulmonary disease, diabetes, cirrhosis, and renal failure (the evidence has been usefully summarised by Mufson $\left.{ }^{7}\right)$. The infections are more severe and the mortality higher in these patients. Although it may be said that pneumonia is the old man's friend, even elderly patients may regard the friend's arrival as premature.

Address for reprint requests: $\operatorname{Dr} \mathbf{R}, \mathbf{T}$ Mayon White, District Department of Community Medicine, Manor House, Headley Way, Headington, Oxford OX3 9DZ.

\section{American policy}

In the United States pneumococcal vaccination is recommended for adults with chronic cardiovascular or pulmonary disease, adults and children aged over 2 years with the conditions that carry an increased risk of pneumococcal disease (see above), and all healthy adults aged 65 or more. ${ }^{8}$ These recommendations are endorsed by the American College of Physicians 9 and the American Academy of Pediatrics, ${ }^{10}$ and reinforced by federal funding : for Medicare to pay for vaccination." Although these recommendations were based on few controlled trials, there is increasing evidence of the efficacy of the 14 polysaccharide vaccine ${ }^{12}$ (see below). But not all the earlier doubts ${ }^{13}$ can be dispelled, as shown by a recently reported controlled trial carried out by the American Veterans Administration. ${ }^{14}$ Moreover, many people entitled to vaccine have not received it: up to 1985 only $10.7 \%$ of adults over 65 years and $7 \cdot 1 \%$ of people in high risk groups in the United States had been vaccinated. ${ }^{15}$ It is timely to consider how pneumococcal vaccine might best be used in other countries.

\section{Modern vaccines}

The present day pneumococcal vaccines are purified type specific polysaccharides, containing $50 \mu \mathrm{g}$ of each type in the 12,14 , and 17 valent vaccines used before 1984 , or $25 \mu \mathrm{g}$ in the newer 23 valent vaccine. These amounts are contained in a volume of $0.5 \mathrm{ml}$ for intramuscular injection. The component types in the vaccines cover $80-90 \%$ of the types causing serious infection. Minor reactions to vaccination are common: mild soreness and induration at the site of the injection in $27 \%$ of 5946 people vaccinated in a double blind controlled trial, with low grade fever in $7 \%$. There were no serious reactions. ${ }^{3}$ Revaccination at intervals of less than five years may cause more severe reactions. $^{16}$ There was a problem with a 14 valent vaccine producing ABO blood group antibodies, ${ }^{17}$ but this difficulty has been overcome with further purification in manufacture. In the United States more than 5 million doses have been given without more serious adverse reactions in people given only one dose. ${ }^{8}$ 


\section{Evidence of efficacy}

The efficacy of pneumococcal vaccines has been assessed by measuring antibody titres after vaccination, by controlled clinical trials, and by surveillance of the incidence of disease in vaccinated people. A single dose of vaccine induces a good antibody response in normal healthy adults, $90 \%$ having a rise in antibody titres to all pneumococcal types. Not so satisfactory is the response in children less than 2 years old and patients with impairment of immunity due to lymphomas, renal failure or asplenism. ${ }^{18-21}$ In these people antigen types $6 \mathrm{~A}, 14,19 \mathrm{~F}$, and $23 \mathrm{~F}$ are less likely to produce antibodies, and the mean post-vaccination antibody titres tend to be less than in healthy adults. For some time there was doubt about the relationship between antibody response and clinical efficacy, but the results of clinical trials suggest that antibody titres below $256 \mathrm{ng}$ immunoglobulin nitrogen $/ \mathrm{ml}$ indicate a lack of immunity. Serum antibody titres, however, are not the only determinant of clinical efficacy because other factors are needed to protect against infection with capsulated bacteria. Patients with chronic obstructive lung disease may produce antibodies but be unable to opsonise pneumococci as well as normal subjects. ${ }^{22} 23$

The early controlled clinical trials of polyvalent polysaccharide vaccines in goldminers in South Africa ${ }^{4}$ and adults and children in Papua New Guinea $^{324}$ produced very promising results. Both groups had a high incidence of pneumococcal pneumonia, which the vaccines reduced by $76-92 \%$. A study in children with sickle cell disease and in children who had had splenectomy also pointed to the vaccine's efficacy, ${ }^{25}$ but a more formal randomised controlled trial in Jamaica, in children under 6 years old with sickle cell disease, found that vaccination was not protective (in contrast to penicillin prophylaxis). ${ }^{26} \mathrm{~A}$ trial by the American Veterans Administration in 2295 patients vaccinated according to the national recommendations found no significant reduction of pneumococcal respiratory infections. ${ }^{14}$ This trial has been criticised because its numbers, although substantial, may have been too small to test efficacy against bacteraemic disease, the key target for vaccination. ${ }^{27}$ Difficulties in achieving significant results and demonstrating protection have also been experienced in trials in elderly people. ${ }^{28}$

Alternative methods of assessing clinical efficacy have been proposed. ${ }^{29}$ In a retrospective study at YaleNew Haven Hospital Shapiro and Clemens ${ }^{30}$ compared the vaccination histories of 90 patients with pneumococcal disease with those of patients matched for age and sex. They estimated that pneumococcal vaccine had an overall efficacy of $67 \%$, or higher if the estimate was calculated for patients aged 55 years or more $(70 \%$ efficacy $)$ and for patients with "moderately increased risk" of pneumococcal infection $(77 \% \stackrel{\overrightarrow{0}}{\stackrel{F}{\circ}}$ efficacy). They could not confirm protection in patients with the highest risk of infection (immuno- 듬 deficiency), but they had few such patients in their $\frac{\bar{D}}{D}$ study. The words "high risk" can confuse: high risk in $\stackrel{\mathbb{Q}}{\Omega}$ the Veterans trial ${ }^{14}$ is similar to moderate risk in the Yale-New Haven study and is applied to patients with chronic pulmonary, cardiac, and renal diseases and $\vec{O}$ alcoholism. By a clever use of the fact that specific $\overrightarrow{\vec{\omega}}$ types are either present or absent from the vaccine, $\stackrel{\omega}{\omega}$ Broome and her colleagues at the Centre for Disease $\vec{x}$ Control, Atlanta, Georgia, devised a means of calculating vaccine protection from reports of $\omega$ pneumococcal bacteraemia and meningitis. ${ }^{31}$ From $\omega$ 187 episodes of bacteraemia in vaccinated people and $\stackrel{f}{G}$ 1447 episodes in unvaccinated patients vaccination 0 was found to be $64 \%$ effective in preventing pneumococcal bacteraemia overall. It was much less 3 effective in patients with Hodgkin's disease, multiple myeloma, and renal failure. ${ }^{32}$

\section{Duration of immunity}

The duration of the raised antibody titres induced by the vaccine is still a matter of uncertainty. Children are $\bar{\partial}$ normally exposed to most if not all of the common $\frac{O}{\square}$

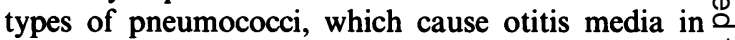
some, with a very small risk (in healthy children) of $\overrightarrow{\overrightarrow{0}}$ pneumonia and meningitis. The natural history of 3 pneumococcal disease implies that immunity declines with age and chronic illness. Pneumococci remain a part of the normal flora of the respiratory tract, so a state of peaceful coexistence may be maintained so $\frac{0}{2}$ long as the host has a competent immune system $\times$ (including a functioning spleen). Presumably there are $\frac{\text { O }}{3}$ times when this condition is not fulfilled and a breach in the defences occurs, so that disease results. Thus the $O$ role of pneumococcal vaccine is to enhance the immunological experience of childhood with reinforc- 욱 ing challenges of antigen. Hence the duration of $D$ immunity is hard to calculate, and must be found by measuring antibodies and observing the incidence of $N$ disease in those who have been vaccinated. Asplenic children and patients having haemodialysis have been 0 found to have falling antibody titres within four years, $\omega$ and they continue to be at risk of pneumococcalo bacteraemia despite vaccination. Repeated vaccina- $\bullet$ tion may be useful in these patients. ${ }^{33-35}$ As a general $\mathbb{\Phi}$ rule, revaccination is not recommended, because of the $\stackrel{?}{?}$ higher incidence of reactions. ${ }^{8}$

\section{Organisation of vaccination}

Patients who have medical indications for pneumococcal vaccine are likely to be receiving con- 
tinuous medical care for their chronic diseases. Vaccination should not therefore be difficult to arrange or unduly expensive by comparison with other drugs. It has been suggested that vaccine should be given when patients are in hospital. ${ }^{36}{ }^{37}$ In the Oxford region 4.8\% of patients who had been in hospital for any reason were readmitted within five years with pneumonia ${ }^{38}$ of whom $34 \%$ might be expected to have pneumococcal pneumonia. ${ }^{39}$ Without evidence from a controlled clinical trial or retrospective evaluation, however, it is not clear whether immunisation in the midst of an acute illness and treatment is fully effective. Many patients who are being treated as outpatients have conditions that double or treble their risks of pneumococcal disease. ${ }^{40}{ }^{41}$ With increased emphasis on prevention in primary care, and the tight financial state of most acute hospital services, there may be a better case for giving the vaccine when the patient is at home. Pilot schemes might be run in several health districts to test the different means of providing vaccine, with monitoring on the uptake of vaccine and the effect on hospital admissions and deaths from pneumococcal pneumonia.

It has been estimated that for every $\$ 6000(1983$ prices) spent on vaccinating 65 year old Americans, one extra year of healthy life is gained.$^{42}$ If protection lasted for eight years and if administrative arrangements were improved, vaccination could have financial as well as humanitarian value. This suggests that other countries should examine the cost-effectiveness of pneumococcal vaccination and compare it with their other public health activities. Modern vaccines require heavy investment in development and manufacture. If little vaccine is used, because of a very selective policy or because physicians show little interest in this form of prevention, there may be no advantage to a pharmaceutical firm in licensing and distributing the vaccine. A substantial investment is required to run good vaccination programmes, not least to win public interest.

\section{Conclusions}

We are near the limits of what can be gained by theoretical arguments without practical experiments in public programmes of pneumococcal vaccination. Given current knowledge, a ready supply of vaccine, and some arbitrary age limits, my policy would be to offer a single dose of 23 valent vaccine to:

1 Patients aged 55-70 with chronic diseases of the heart, lungs, or liver or with diabetes, provided that they were not expected to die from their underlying condition within the next year. The vaccine should be given when the patient is not acutely ill.

2 Patients aged 2-70 with chronic renal disease, sickle cell disease, or asplenism, again at a time when they are not acutely ill. The vaccine should preferably be given before splenectomy (if applicable) and certainly not during periods of intense immunosuppression. Because vaccination is not reliable in these conditions, the patients should be advised to seek medical advice at the first symptoms of infection. Children with sickle cell disease or other forms of asplenism should in addition have penicillin prophylaxis.

The vaccination should be clearly recorded in the hospital and general practice notes. The usage of vaccine should be monitored nationally, and its efficacy should be assessed periodically by retrospective studies. These require accurate diagnosis of pneumonia, with pneumococcal typing of all relevant isolates.

As the vaccines have not proved effective in reducing pneumococcal bacteraemia in patients with multiple myeloma or Hodgkin's disease, these conditions are not included in my list of indications. Vaccination in pregnancy is not recommended. At present, revaccination is not indicated, even for those who were given 14 valent vaccine several years ago.

When we have vaccinated most if not all patients in the higher risk groups, we should consider whether the benefits (if such they are) can be shared more widely. I look foward to the time when pneumococcal vaccination is part of everyone's preretirement course.

\section{RT MAYON WHITE District Department of Community Medicine Oxford}

\section{References}

1 Austrian R. Random gleanings from a life with the pneumococcus. J Infect Dis 1975;131:474-84.

2 Austrian R. The current status of bacteraemic pneumococcal pneumonia. Re-evaluation of an under emphasised clinical problem. Trans Ass Am Phys 1963;76:117-25.

3 Riley IR, Tarr P, Andrews M. Immunisation with a polyvalent pneumococcal vaccine: reduction in adult respiratory mortality in a New Guinean highlands community. Lancet 1977; ;:1338-41.

4 Smit P, Oberholzer D, Hayden-Smith S, et al. Protective efficacy of pneumococcal vaccines. JAMA 1977;238:2613-6.

5 Woodhead MA, Macfarlane JT, McCracken JS, Rose DH, Finch RG. Prospective Study of the aetiology and outcome of pneumonia in the Community. Lancet 1987;i:671-4.

6 Macfarlane JT, Finch RG, Ward MJ, Macrae AD. Hospital study of community-acquired pneumonia. Lancet 1982;ii:255-8.

7 Mufson MA. Pneumococcal Infections JAMA 1981; 
246: $1942-8$.

8 Immunization Practices Advisory Committee. Update: pneumococcal polysaccharide vaccine usage-United States. Morbidity and Mortality Weekly Report 1984:33:273-6.

9 Health and Public Policy Committee, American College of Physicians. Pneumococcal vaccine. Ann Intern Med 1986;104:118-20.

10 Committee on Infectious Diseases, American Academy of Pediatrics. Recommendations for using pneumococcal vaccine in children. Pédiatrics 1985;75:1153-8.

11 Riddiough MA. Federal policy for pneumococcal immunization and its implementation in the Medicare programme. Infect Control 1982;3:309,310,315.

12 LaForce FM, Eickhoff TC. Pneumococcal vaccine: the evidence mounts. Ann Intern Med 1986;104:110-2.

13 Hirschmann JV, Lipsky BA. Pneumococcal vaccine in the United States: a critical appraisal. JAMA 1981;246:1428-32.

14 Simberkoff MS, Cross AP, Al-Ibrahim M, et al. Efficacy of pneumococcal vaccine in high-risk patients. $N$ Engl J Med 1986;315:1318-27.

15 Fedson DS. Influenza and pneumococcal immunisation strategies for physicians. Chest 1987;91:436-43.

16 Borgono JM, McLean AA, Vella PP. Vaccination and revaccination with polyvalent pneumococcal polysaccharide vaccines in adults and infants. Proc Soc Exp Biol Med 1978; 157:148-54.

17 Noel A. Anti-A isoagglutinins and pneumococcal vaccine. Lancet 1981;ii:687-8.

18 Douglas RM, Paton JC, Duncan SJ, Hansman DJ. Antibody response to pneumococcal vaccination in children younger than five years of age. $J$ Infect Dis 1983;148:131-7.

19 Addiego JE, Ammann AJ, Schiffman G. Response to pneumococcal polysaccharide vaccine in patients with untreated Hodgkin`s disease. Lancet 1980;ii:450-3.

20 Cosio FG, Giebank GS, Le CT, Schiffman G. Pneumococcal vaccination in patients with chronic renal disease and renal allograft recipients. Kidney Int 1981;20:254-8.

21 Hosea SW, Burch CG, Brown EJ, Berg RA, Frank MM. Impaired immune response of splenectomised patients to polyvalent pneumococcal vaccine. Lancet $1981 ; \mathrm{i}: 804-7$.

22 Landesman SH, Smith PM, Schiffman G. Pneumococcal vaccine in elderly people with chronic obstructive pulmonary disease. Chest 1983;84:433-5.

23 Musher DM, Chapman AJ, Goree A, Jonsson S, Briles D, Baughn RE. Natural and vaccine-related immunity to Streptococcus pneumoniae. J Infect Dis 1986:154:245-6.

24 Riley ID, Everingham FA, Smith DE, Douglas RM. Immunization with a polyvalent pneumococcal vaccine: effect on respiratory mortality in children living in the New Guinea highlands. Arch Dis Child 1981:56:354-7.

25 Ammann AJ, Addiego J, Wara DW, Lubin B, Smith WB, Mentzer WC. Polyvalent pneumococcal-polysaccharide immunization with sickle-cell anaemia and patients with splenectomy. N Engl J Med 1977;297:897-
900

26 John AB, Ramlal A, Jackson H, Maude GH, Sharma AW, Serjeant GR. Prevention of pneumococcal infection in children with homozygous sickle-cell disease. $\mathrm{Br}$ Med J 1984;288:1567-70.

27 Shapiro ED. Pneumococcal vaccine failure. $N$ Engl J Med 1987;316:1272-3.

28 Bentley DW, Ha K, Mamot K, et al. Pneumococcal @ vaccine in the institutionalised elderly: design of a nonrandomised trial and preliminary results. Rev Infect Dis 1981;3:S71-81.

29 Clemens JD, Shapiro ED. Resolving the pneumococcal vaccine controversy: are there alternatives to randomised clinical trials? Rev Infect Dis 1984;6:589-600.

30 Shapiro ED, Clemens JD. A controlled evaluation of the $\vec{\omega}$ protective efficacy of pneumococcal vaccine for patients $i$ at high risk of serious pneumococcal infection. Ann Intern Med 1984;101:325-30.

31 Broome CV, Facklam RR, Fraser DW. Pneumococcal disease after pneumococcal vaccination: an alternative method to estimate the efficacy of pneumococcal vaccine. $N$ Engl J Med 1980;303:549-52.

32 Bolan G, Broome CV, Facklam RR, Plikaytis BD, Fraser DW, Schlech WF. Pneumococcal vaccine efficacy in selected populations in the United States. Ann Intern Med 1986;104:1-6.

33 Geibank GS, Le CT, Schiffman G. Decline in serum antibody in splenectomized children after vaccination with pneumococcal capsular polysaccharides. $J$ Pediatr 1984;105:576-82.

34 Nikoskelainen J, Koskela M, Forsstrom J, Kasanen A, Leinonen M. Persistence of antibodies in patients with chronic renal failure. Kidney Int 1985;28:672-77.

35 Linneman CC, First MR, Schiffman G. Revaccination of renal transplant and haemodialysis recipients with pneumococcal vaccine. Arch Intern Med 1987;146: 1554-6.

36 Fedson DS, Chiareilo LA. Previous hospital care and pneumococcal bacteraemia: importance for pneumococcal immunization. Arch Intern Med 1983, 143:885-9.

37 Klein RS, Adachi N. An effective hospital-based pneumococcal immunization program. Arch Intern Med 1986;146:327-9.

38 Fedson DS, Baldwin JA. Previous hospital care as a risk factor for pneumonia: implications for immunization with pneumococcal vaccine. JAMA 1982;248:1989-95.

39 British Thoracic Society Research Committee. Community-acquired pneumonia in British hospitals in 1982-83: a survey of aetiology, mortality, prognostic factors and outcome. $Q J$ Med 1987;62:195-220.

40 Lipsky BA, Boyko EJ, Inui TS, Koepsell TD. Risk factors for acquiring pneumococcal infections. Arch Intern Med 1986;146:2179-85.

41 Magnussen RC, Valenti WM, Mushlin AI. Pneumococcal vaccine strategy: feasibility of a vaccination program directed at hospitalized and ambulatory patients. Arch Intern Med 1984;144:1755-7.

42 Sisk JE, Riegelman RK. Cost effectiveness of vaccination against pneumococcal pneumonia: an update. Ann Intern Med 1986;104:79-86. 